\title{
ILCEA
}

Revue de l'Institut des langues et cultures

d'Europe, Amérique, Afrique, Asie et Australie

22 | 2015

La révolution théâtrale dans le Río de la Plata

\section{Subjetividad poética: aplicación y sistematización en la escena, el caso de La Organización Negra}

Subjectivité poétique : application à la scène, le cas de La Organización Negra (L'Organisation noire)

Poetical Subjectivity: Application to the Theatre Scene, the Case of

La Organización Negra (The Black Organization)

\section{Carla Pessolano}

\section{OpenEdition}

\section{Journals}

Edición electrónica

URL: http://journals.openedition.org/ilcea/3206

DOI: $10.4000 /$ ilcea.3206

ISSN: 2101-0609

Editor

UGA Éditions/Université Grenoble Alpes

Edición impresa

ISBN: 978-2-84310-295-0

ISSN: $1639-6073$

Referencia electrónica

Carla Pessolano, « Subjetividad poética: aplicación y sistematización en la escena, el caso de La Organización Negra », ILCEA [En línea], 22 | 2015, Publicado el 01 marzo 2015, consultado el 20 abril 2019. URL : http://journals.openedition.org/ilcea/3206 ; DOI : 10.4000/ilcea.3206

Este documento fue generado automáticamente el 20 abril 2019.

(C) ILCEA 


\title{
Subjetividad poética: aplicación y sistematización en la escena, el caso de La Organización Negra
}

\author{
Subjectivité poétique : application à la scène, le cas de La Organización Negra \\ (L'Organisation noire) \\ Poetical Subjectivity: Application to the Theatre Scene, the Case of \\ La Organización Negra (The Black Organization)
}

\section{Carla Pessolano}

1 A partir de nuestra formación y práctica que incluye lo artístico en articulación con la investigación, nos propusimos plantear una sistematización de procesos actorales en función de la noción de subjetividad poética que venimos desarrollando desde hace un tiempo. Tomando como punto de partida para la misma la mirada que construye el artista acerca de su propia práctica para ver cuáles son las herramientas que utiliza éste para pensar y describir su praxis. Para la aplicación de la noción utilizaremos un grupo que es un referente muy singular de la época de Postdictadura inmediata en Argentina, La Organización Negra. Y de este modo veremos el tipo de análisis de la subjetividad poética aplicado a un caso en particular.

\section{Subjetividad poética: la reflexión acerca del proceso creativo}

2 A continuación desarrollamos la noción de subjetividad poética y sus componentes principales. Ante todo resulta interesante pensar cuál es el tipo de poética ${ }^{1}$ que constituye a un sujeto artístico y de qué manera cada poética puede ser estudiada a partir de sus particularidades y del tejido que se establece entre el creador y su contexto.

3 Tibor Bak Geler hace referencia a que el abordaje del estudio sobre las ciencias del arte desde la mirada del propio artista tiene a favor el conocimiento de la materialidad de su 
objeto de estudio. El autor plantea evitar la separación entre el estudio científico en esta área (escindido de la propia experiencia artística). Luego, al hacer referencia a las artes escénicas también alude a que éstas requieren un tipo de estudio fragmentado (por su singularidad intrínseca y por resultar imposible aprehenderlas en su totalidad). A raíz de esto dice: "Entender el proceso de génesis de una obra artística es fundamental para el estudio de las artes porque permite superar toda ficción impuesta sin conocimiento de causa" (Bak Geler, 2003: 87).

Haciendo pie en la propuesta de este teórico respecto de la sistematización de las propias prácticas creadoras, en combinación con el aporte de los elementos que surgen directamente de la escena ${ }^{2}$, es como nos proponemos trabajar sobre nuestra categorización de subjetividad poética.

\section{La subjetividad poética del actor}

5 Este concepto hace pie sobre la práctica teatral pero toma cuestiones de diversas artes y otras disciplinas (literatura, filosofía, sociología, etc.) para configurarse como tal. Se parte del concepto de subjetividad acuñado por Michel Foucault (1968). Según este autor, el hombre produce discurso a partir de su subjetividad (sus ideas, su vida, sus experiencias) y es a partir de las marcas de experiencia que el texto escrito (en este caso la obra artística) tiene la posibilidad de condensar fuerzas que pueden ser reactivadas durante la lectura. De este modo, se puede hacer la comparación con el arte escénico, en función del recorrido del actor, que pone en juego sus experiencias precedentes en su actuación. Según Foucault, el sujeto forma parte de su devenir histórico. No es un sujeto que constituye por sí mismo su realidad, sino un sujeto constituido por las relaciones que se ponen en juego en el interior de una estructura dada. Del mismo modo, el artista genera discurso en relación a su propia subjetividad.

Por su parte, la subjetividad en el arte se produce específicamente en el siguiente entrecruzamiento: el hecho artístico y la importancia de su autor se conforman en tanto éste es atravesado por su obra (Deleuze, 1987). Si bien cada disciplina tiene su propia singularidad creativa, es en función de la misma que un autor se ubicará en determinado lugar para hablar acerca del mundo. De este modo, podemos encontrar universos próximos constituyéndose en contextos diferentes (es así como vemos ciertos universos similares en autores de realidades diferentes). Son las líneas de fuga (Deleuze, 1987) las que pueden atravesar el tiempo para volverse acontecimiento (Scherer, 1999).

7 Luego, hemos tomado la noción de subjetividad poética desde la literatura. Pierre Ouellet y Laura Scarano mencionan la subjetividad poética como la relación del autor con su obra. En el caso de Ouellet propone un ejemplo concreto, él dice: si bien el lector no degustará nunca la madalena de la cual habla Proust, es en la construcción de su relato que comprendemos lo que el héroe siente, percibe y vive cuando la degusta. Es en este punto que el lector percibe la intimidad de la mano del autor y la razón por la cual se puede hacer una analogía con el arte teatral. En sus procedimientos, el actor utiliza herramientas de su vida personal para su elaboración creativa. Entonces queda profundizar en qué punto esto puede encontrarse más cerca de sus recursos experienciales o de sus recursos profesionales; además de ver cómo el actor se mira a sí mismo a la hora de sistematizar sus propias prácticas (si es que lo puede hacer). Cuando la investigadora Laura Scarano habla de una subjetividad se refiere a los recursos que posee el escritor para construir relato con una profunda cercanía a su vida -en palabras de la 
autora: "reflexión sobre los mecanismos discursivos del arte, desde la implicación del cuerpo, los sentimientos y la intimidad" (Scarano, 2008: 1). Ella basa su trabajo en lo experiencial, específicamente en relación al poema. Por lo tanto esta noción de experiencia cuenta en sí misma sus modos de formulación poética, ya que en la práctica textual emerge una intimidad verbalizada y el lector es perfectamente capaz de percibirla:

Lo vivido emergía contado y transmitido por alguien que decía "yo". La experiencia de uno (inaccesible para otros, incorpórea en su antes y afuera del momento de la inscripción verbal) "tomaba cuerpo en la palabra" y de algún modo -errático, limitado e imperfecto- era susceptible de comunicación. A diferencia de esas otras ficciones inverosímiles y fantásticas que me remontaban siempre a mundos lejanos y desconocidos, en estos otros textos intuía que podía reconocer mi propia experiencia reflejada en la letra de algún modo indirecto y siempre relativo, pero eficaz (Scarano, 2007: 17).

8 He aquí la razón por la cual nos hemos preguntado por este tipo de vínculo entre el artista y su obra, que llamamos subjetividad poética. A continuación veremos cómo ésta puede contar con diversas "boyas" para llegar a definirla de manera multidimensional (es decir no sólo a partir de los relatos de procesos, ni a partir de resultados estéticos, sino algo más global y a la vez particular en cada caso).

\section{Componentes de la subjetividad poética}

Según lo que hemos desarrollado en nuestro trabajo de maestría podemos hablar de dos variables dentro del análisis del artista escénico y sus prácticas creativas: el tiempo y el espacio (por decirlo de manera global). De este modo, podemos plantear la noción de subjetividad poética del actor concerniente a los procesos de creación, y podemos diferenciar entre: a) selección del objeto de trabajo; b) selección de los materiales que sirven a la construcción de este objeto de trabajo; c) selección concerniente al texto dramático-espectacular y d) configuración de la poética singular final. Por otro lado, en relación a la subjetividad poética del actor concerniente a los diferentes marcos contextuales, hacemos la división entre el contexto global (marco político, histórico, social del trabajo de una puesta en escena, con diversos niveles de incidencia sobre la producción y la recepción del trabajo) y el contexto específico del artista (marco de producción dentro del cual el artista ha llegado a desarrollar este objeto artístico y no otro).

\section{Subjetividad poética del actor concerniente a los procesos de creación}

A continuación desarrollaremos con más detalle cada una de las instancias del desarrollo de la subjetividad poética, en relación a los procesos de creación.

a. Selección del objeto de trabajo: Situación de pre-escena, la forma más primaria de abordaje de un proceso, desde lo estético, lo textual, lo temático, el mundo a indagar, etc. Es el primer acercamiento a un material que puede devenir en cualquier otra cosa (generalmente una idea original muta a través del proceso creativo, dependiendo de múltiples variables).

b. Selección de los materiales que sirven a la construcción de este objeto de trabajo: Proceso e investigación en relación a la escena; sus niveles de profundidad dependerán del tiempo y del tipo de ensayos. Este punto se puede analizar a partir del enfoque grupal, en la 
concepción de teatro que se constituye en colectivo para el abordaje del material escénico y, a su vez, en el recorrido personal de cada actor para el tránsito del personaje. Serían los primeros recursos para el abordaje de un material nuevo (por dónde encararlo), como reflexiona acerca de sus propios procesos Francis Bacon cuando habla sobre el accidente.

c. Selección concerniente al texto dramático/espectacular: Enfoque del texto que comienza en un lugar y termina en otro. Esto podría llegar a ser aleatorio, en función del proceso, del contexto, del tiempo que haya hasta el estreno, de la mirada que constituye la totalidad de la obra, etc. Todas éstas y otras son las condiciones que terminan generando determinado hecho artístico y no otro. Cuando el artista finaliza su obra (fin del acto creador -se podría decir - tomando la instancia de ensayos como un fin en sí mismo, luego comenzando otra instancia muy diferente) ésta queda en un umbral a partir de la cual se puede convertir en cualquier otra cosa. Es, con su propia entidad, algo inacabado; su configuración de sentido no se agota al momento en que decide salir a la luz (Deleuze).

d. Configuración de la poética singular final: Recorrido en pura subjetividad, en función del pasaje por todos los puntos anteriores. Utilizando en términos comparados las nociones de Barthes en relación a la literatura, podemos decir que este punto se termina de completar en la recepción del hecho artístico: cuando el nacimiento del lector se paga con la muerte del Autor (Barthes, 2009).

\section{Subjetividad poética del actor según los diferentes marcos contextuales}

\section{Contexto global}

El contexto dentro del cual un artista inscribe su obra le va a dar su marco de referencia y el aporte de su propia mirada acerca del mundo. Retomando lo que planteamos anteriormente por Foucault y llevándolo en esta ocasión específicamente al campo del arte, podemos decir que la actividad artística es, en toda su singularidad, el reflejo permanente del artista que lo produce. El arte se ofrece, entonces, como un discurso de lo imaginario, del pensamiento abstracto y de su complemento racional. En el punto en que el arte es el reflejo de la vida (de su contexto, de su entorno), podemos decir que es asimismo en este procedimiento que el arte se constituye como emancipador del sujeto.

Alain Badiou (2012), por su parte, hace una diferenciación que consideramos pertinente citar en relación a esta idea, entre la noción de sujeto para la psicología y la filosofía. El autor dice que para la primera disciplina, el sujeto se encuentra sometido a determinaciones fundamentales que lo constituyen como tal. Es desde el momento de su nacimiento que éste es insertado en una estructuración (mundo) ya determinada. Por lo tanto, el sujeto en sí mismo sería el destino de un cuerpo en particular, se trataría de una condición de posibilidad del sujeto, que el autor elige llamar figura pre-subjetiva. Para el caso de la filosofía en cambio (y de la suya en particular) esta figura pre-subjetiva tiene la posibilidad de devenir un verdadero sujeto, en tanto los acontecimientos particulares que transite le permitan hacerlo, mediante la inserción a un código específico. Es decir, éste toma entidad de sujeto en la relación que establece con una verdad determinada. Podemos hablar entonces de un sujeto del arte, un sujeto científico, un sujeto político, etc. Es decir un sujeto de su coyuntura (rol social). 


\section{Contexto específico del artista}

13 Elka Fediuk, teórica, docente y actriz teatral polaca describe en su texto "Herencias y exilios" el contexto específico dentro del cual Grotowski funda el Teatro Laboratorio:

Durante el periodo 1795-1918 Polonia padeció la ocupación a causa de la voracidad de sus tres vecinos: Prusia, Rusia y Austria [...] los ocupantes impusieron en sus territorios su lengua como oficial. En algunas regiones se logró parcialmente preservar en las escuelas la lengua polaca, pero desde los escenarios de Cracovia, Lvov, Varsovia y otras ciudades se podía escuchar el más perfecto idioma polaco cultivado por los artistas conscientes de su rol patriótico en este menester (Fediuk, 2011: 29).

He aquí el rol fundamental de la escena teatral dentro de la coyuntura específica de la vida en opresión (en este caso específico tomando como ejemplo la lengua tradicional de un país). En este punto podemos tomar este ejemplo para ver cómo el contexto afecta a las personas que llevan adelante el desarrollo de su producción artística. Hoy en día escuchar hablar polaco en un teatro de Polonia no tiene la misma carga que en ese momento, así como no es lo mismo representar hoy en día Telarañas (de Eduardo Pavlovsky) en Argentina que en 1982, durante la dictadura. Es su entorno y la recepción lo que hace "actuar" a la obra de manera diferente.

\section{La Organización Negra: teatro de Postdictadura inmediata}

15 La Organización Negra, es una formación teatral argentina fundada en 1984 y que se mantuvo bajo ese nombre hasta 1986, año en que se estrena el espectáculo llamado "UORC". Si bien en el grupo hubo varias incorporaciones y deserciones, variando en etapas, la formación en estos primeros años contó con la presencia de Marcelo Acuña, Daniel Algarbe, Pichón Baldinu, Pol Barral, Fernando Dopazo, Carlos Feijoo, Manuel Hermelo, Gabriel Kerpel, Charly Nijenshon, Gustavo Niño, Ariel Pumares y Alfredo Visciglio. Este grupo que se caracterizó originalmente por trabajar a partir de escenas espontáneas en la calle, luego llegó a actuar en espacios cerrados, constituyendo lo que detectamos como la gran singularidad de su poética.

\section{Aplicación}

\section{Subjetividad poética y procesos de creación}

\section{Selección del objeto de trabajo}

Tomando como referencia un espectáculo del grupo catalán "La Fura del Baus" que vieron durante un festival de teatro, el grupo argentino va a comenzar a producir escenas en espacios públicos. Se trató de sus primeras experimentaciones llamadas "ejercicios de calle" o como también solían decirles "ejercicios de guerrilla", por ejemplo: La procesión papal (caminaban por la calle Florida, había un Papa y un séquito de tullidos y minusválidos que lo acompañaban), Encadenamientos (en el cruce de las avenidas Callao y Santa Fe había Modelos Vivos ${ }^{3}$ encadenados a los semáforos que gemían), Canto de Villancicos en los semáforos (lo llamaban ejercicio gótico, lo hacían en la intersección de dos 
grandes avenidas con vestuarios "depresivos"), Chanchazos (entraban camilleros en galerías del centro porteño llevando cuerpos de hombres y cabezas de chanchos), Imaginaria del Fusilamiento / Muerte en el asfalto (había un grupo de Modelos Vivos vestidos de civil de un lado de una avenida y otro grupo del otro lado, cuando lo habilitaba el semáforo cruzaban junto con los transeúntes y se escuchaba el estruendo de armas de fuego y varios caían desplomados frente a los autos. La gente seguía cruzando, los Modelos Vivos se paraban y seguían caminando4), El vomitazo (los Modelos Vivos iban caminando por la calle y cuando cortaba el semáforo se paraban y vomitaban yogur arriba de los autos, eran varios en simultáneo para agarrar a todos los autos que iban por la avenida). Luego de algunos de estos ejercicios repartían panfletos con imágenes provocativas y en el dorso unas frases dirigidas a los transeúntes que las recogieran incluyendo, por ejemplo, la receta del fainá y un texto que argüía "No nos gustás".

Como podemos ver, estas intervenciones en el espacio-ciudad apuntaban a generar una ruptura en la cotidianeidad, buscando situaciones de choque y de enfrentamiento directo al público (en este caso al espectador espontáneo que andaba por la calle). Y derivado de esto comienzan a montar un guión de operaciones al que denominarán "operaciones de sensaciones". Surgiendo principalmente en oposición al teatro que llamaban tradicional (que para estos creadores era el teatro basado exclusivamente en el texto) "como un hecho arqueológico" que se hallaba "desfasado de la realidad social"5. Llevaban a cabo esta investigación a partir de su formación principalmente teatral, pero con la premisa de embarcarse en un trabajo que tendría que ver más con la imagen que con el concepto, más con el cuerpo que con la mente, según los dichos de sus participantes.

\section{Selección de los materiales que sirven a la construcción de este objeto de trabajo}

En este marco, podemos hablar de las formas de producción de la agrupación (cómo se reunieron, cómo trabajaron) y los elementos que fueron conformando su poética. Luego de su búsqueda en el espacio de la calle, ellos sabían que lo que querían para su primera obra en un espacio cerrado (espacio teatral) era provocar al espectador, y ese fue el criterio con el que armaron el equipo de trabajo.

Respecto de la concepción de grupo que los nuclea, cabe destacar que los actores no se encontraban en relación a una idea preconcebida por otro, ni esperando las indicaciones de un director, sino que sintetizan un universo en común, en su doble recorrido, como intérpretes y creadores de su obra. Es así que los roles y la división de las actividades se organizaban en una estructura interna para ocuparse de las cuestiones de producción (por ejemplo, las funciones eran los jueves y salían los lunes en pares por Once a buscar cosas para la escenografía: tubos fluorescentes, cartón, etc.); también la dirección y el montaje se llevaban a cabo en grupo, tomando decisiones en conjunto. El arreglo económico era en cooperativa, a todos les tocaba la misma cantidad.

Se podría decir que la búsqueda artística que los definió en ese primer momento era la intención de generar un impacto a nivel sensorial, produciendo un entretejido múltiple donde fuera imposible prestar atención a un solo elemento de la escena. Según la descripción de los creadores, la búsqueda era generar "estados" en un espectador que no puede permanecer pasivo ante el "ataque" de estímulos en varios niveles. 


\section{Selección a partir del texto dramático/espectacular}

21 Durante la configuración de la poética de la agrupación, y como un aporte fundamental a la misma, se desarrolló un detallado glosario. En éste podemos ver hasta qué punto la mirada sobre su propia producción era específica. Evidentemente tenían noción de la novedad de su planteo escénico, por lo tanto, necesitaban generar un código, instruir al espectador, establecer un sistema de creencias en relación a su impronta. Indudablemente, como parte de su investigación esta forma de apropiación de las zonas sobre las que indagaban los ayudaba a encontrarse con su propio material escénico, zona singular y genuina de los recursos grupales. Nombrar para "fundar mundo", se hallaban todo el tiempo en esa búsqueda porque era la forma de articular lo poético con la práctica.

Recalquemos que se nombra por fuera de lo espectacular, porque el lenguaje no es la herramienta que eligen tomar para significar. Más bien todo lo contrario, se resisten a él (en términos dramáticos, textuales) en su puesta en escena. Este es uno de los elementos que, consideramos, le otorgan mayor singularidad a esta poética. En diálogo con Dopazo reafirma esta paradoja:

Nosotros poníamos los nombres. Nomenclar funcionaba como una parte fundamental en la fundación poética, lo demás iba solo [...] tomábamos mucho de la estética nuclear, y del cómic (como Ops) sobre todo porque eso tenía ya de por sí una ruptura con la narración, con o sin palabras ${ }^{6}$.

\section{Configuración de la poética singular final}

En este punto de nuestra sistematización podemos agregar el cruce de disciplinas y el glosario que nombramos anteriormente, así como la relación de la agrupación con el espectador. La relación con éste era primordial dado que consideraban que el público encarnaba una zona de multiperspectiva fundamental. Por lo general, la gente que presenciaba el espectáculo salía muy movilizada ya que, si bien el espectáculo no era participativo en su concepción, el espectador "reaccionaba por obligación" en función del recorrido trazado a tal fin. Por lo tanto, había participación sin dejar de estar del lado receptor. Generalmente, el público se limitaba a correr, gritar, esconderse o incluso confrontar a los Modelos Vivos?

En relación a la recepción, su primer espectáculo tuvo mucha convocatoria. Este grupo fue producto de una posición singular en relación a una práctica teatral ya que priorizaba lo popular, lo que permitía que se acercara un público de intereses diversos (según describen los artistas quizá alguien que iría a una fiesta pero no al teatro o al cine). Este valor de identificación de amplio alcance incorpora un espectador que no requiere un conocimiento más específico de la escena que simplemente ganas de ser atravesado por un hecho artístico singular.

Cabe destacar que esta agrupación de Postdictadura no fundaba este tipo de prueba escénica como búsqueda de llegar a la profesionalización, como un paso de producción escalonado hacia el encuentro con la tarea del profesional en teatro. Querían producir efecto y ese espectáculo representaba un anhelo compartido, una ideología, forma de producción política y estética, creencia artística en sí misma. El under era una manera de estar corrido de la idea que tenían del "teatro bien hecho" (el teatro "de texto", gran fantasma de ese momento y para este grupo en particular) ser punks en el ámbito teatral, 
decir lo que no se podía decir de otra manera, hacer estallar los límites y descolocar al espectador, fundiéndolo en una experiencia irracional y desmesurada de sensaciones múltiples.

Se basaron en un concepto espectacular, no sostenido en un hilo argumental sino en la apelación total a los sentidos del espectador. De esta manera, en cada presentación, el público, cual observador-participante, se sumergía en el vertiginoso ritmo de un hecho artístico sustentado fundamentalmente en la generación de climas y sensaciones. Esta praxis teatral que incluye la ruptura de la disposición espacial dividida espectador-actor, se sostiene en la creencia en un espectador activo sensiblemente e inquieto para circular y captar la mayor cantidad de imágenes posibles que se proponen en el espacio escénico. Esto da una clara pauta de la concepción de teatro que manejaba este grupo, con una marca generacional que los representa. En relación con sus recursos y el vínculo con la escena, este detallado glosario los conforma como artistas, ya que es ésta la reflexión más específica que podemos ver del grupo en relación a su práctica. Aunque sean resistentes a la idea de texto en la puesta en escena, este lenguaje propio (a partir del momento exacto de comenzar su búsqueda) ha conformado en gran parte su Subjetividad poética en tanto creadores.

\section{Subjetividad poética según los diferentes marcos contextuales}

\section{Contexto global}

El contexto histórico en el cual se inserta el grupo es la Postdictadura inmediata (1984). Como parte de la producción teatral de los '80, La Organización Negra se inscribió en un panorama teatral extremadamente heterogéneo, con una poética en la que se destacaba la multiplicidad, caracterizándose por desarrollar una búsqueda escénica y un concepto artístico a partir de la fricción y el contacto físico con el espectador. El espíritu festivo del principio de la democracia contextualizaba esta búsqueda en un clima de mucha euforia que teñía a la cultura del momento, en todas las disciplinas artísticas. En el caso del teatro, regido por la utilización de ámbitos no tradicionales para la puesta en escena: sótanos, galpones, cafés, etc. -puntos de encuentro para performances y espectáculos de toda índole que satisficieron las necesidades expresivas de muchos artistas luego de años de censura (Amigo, 2011) - el ritmo de creación era veloz y la exposición alta, en busca de un universo artístico diferente y provocativo, que transgredía los espacios de acción hasta dejarlos prácticamente sin fronteras. Si bien en este grupo podemos decir que no se actúa con un correlato directo a los procesos sociales que se sucedían en el momento de su producción, de alguna manera, la puesta en escena funcionaba como un reflejo de una voluntad transformadora de los mismos.

\section{Contexto específico del artista}

La fuerza de "la negra" radica, justamente, en que se apoya en una espontaneidad incontrolable, que impulsa sin pretender canalizar, sin pretender utilizar en beneficio propio la acción que ha puesto en marcha. Comience su propio incendio, la negra no piensa por usted ${ }^{8}$. 
28

un grupo de estudiantes de la Escuela Nacional de Arte Dramático forma La Lista Negra con el fin de presentarse a las elecciones del Centro de Estudiantes "como movimiento que respondía a la contestación chabacana que había en ese lugar" (Pisani, 1986), agrupación luego devenida en La Organización Negra.

Al margen de esta práctica, y sostenidos por la noción de grupo que los conforma, comienzan a hacer pruebas escénicas sistematizándolas. Luego, son invitados como parte del estudiantado del Conservatorio al Festival Internacional de Teatro Latinoamericano en Córdoba, y es allí donde ven por primera vez al grupo catalán "La Fura dels Baus" con su espectáculo Accions. Motivados por esto y con una necesidad ya incontenible de "producir escena" se organizan de manera tal que puedan lograr aquello a lo que aspiraban: provocar un fenómeno. Por lo tanto, si bien ya venían produciendo y estudiando por su cuenta, esta nueva situación los llevó a modificar su estilo de trabajo conocido para comenzar con un teatro definidamente "de choque". La estética que los caracterizaba era un clima industrial, de demolición y violencia (algunos de los elementos resonantes del grupo catalán arriba mencionado, así como el trabajo con el sonido, la temática postnuclear y la búsqueda de generar impacto), que los incentivaba a indagar en esos aspectos. Instalándose de ese modo como un grupo que contaba con una poética singular y reconocible en el teatro underground porteño de la época, lograron innovar la escena teatral argentina.

\section{Síntesis}

Hemos visto los preceptos que les son próximos a su práctica artística, a su pensamiento y que están presentes durante los procesos de creación de los artistas de La Organización Negra. Podríamos mencionar, generalizando, los siguientes: oponerse al teatro que ellos consideraban tradicional, alejarse de la relación con el texto, producir un impacto en el espectador y producir un tipo de teatralidad que se apoye en la imagen y el cuerpo.

Como se dijo con anterioridad, el contexto en el cual el artista inscribe su obra le va a dar su marco de referencia, así como su propia mirada acerca del mundo. Aunque podemos confirmar (por entrevistas con sus integrantes) que esta agrupación no intentaba demostrar un correlato lineal con los procesos sociales que se sucedían en ese momento de la Argentina, podemos afirmar que, sin ser programático, el trabajo en relación a la escena pretendía tener una incidencia sobre los mismos. Si bien este grupo se planteaba objetivos globales en relación a su propuesta artística, ha resultado interesante ver cómo llegan a hacer una aguda sistematización sobre sus prácticas, principalmente a través de las descripciones de los términos que salían de su praxis.

De este modo se describe a sí mismo el grupo en el glosario que forma parte del programa de mano del espectáculo UORC:

La Organización Negra son:

Gustavo Niño, Alejandro Pichón Baldinu, Fernando Dopazo, Pol Barral, Ariel

Pumares, Manuel Hermelo, Alfredo Visiglia, Carlos Feijoo, Daniel Algarbe, Charly

Nijensohn.

Banda de sonido:

Gabriel Kerpel.

La Organización Negra, organización de color negro.

Condensación y precipitación del accionar negro. Se dice también de una estrategia teatral y de esa animosidad leve por destruir. No se trata de la simulación de la violencia. Se trata de la simulación de lo teatral. 
Hay también la seducción por las ruinas despedazadas. Por los restos carbonizados de un siniestro, por el paisaje calmo y descuidado que precede a una gran catástrofe. La Organización Negra elige lo urbano en su total magnitud, la mirada calva y post-industrial de nuestra mente.

Hay imágenes que anuncian la nueva ceremonia.

\section{Conclusión}

En el presente trabajo nos hemos basado en dos ejes específicos para llegar a ver la sistematización de prácticas creadoras en el caso de un grupo teatral específico. Por un lado hemos desarrollado brevemente la noción de subjetividad poética, que es una propuesta que planteamos en relación a categorías que surgen directamente de la praxis teatral. Por otro lado tenemos el antecedente de investigación sobre un grupo teatral específico que nos ha servido para desarrollar la aplicación de la noción. En relación a esto nos resulta interesante ver cuáles son las singularidades de una agrupación de este tipo para definirse en tanto sujetos artísticos, a partir de la óptica que nos provee la sistematización que hemos propuesto al principio. Así como existen artistas teatrales que son muy agudos en la lectura acerca de su evolución artística y maneras de producción específica, la gran particularidad que encontramos en La Organización Negra es la manera en la que se auto-describen a partir de un glosario detallado y profundamente reflexivo. Suponemos que en cada poética podemos encontrar un elemento clave, como nos fue éste, para profundizar en su singularidad. Pero esto no sería posible sin el aporte de los artistas dialogando acerca de sus prácticas. Es por esto que consideramos interesante la aplicación de la subjetividad poética a otras prácticas escénicas y de manera comparada entre varias de ellas. Proponemos al lector, que así lo desee, servirse de ella y reflexionar acerca de una práctica artística específica ya que resulta una experiencia enriquecedora para pensar el teatro.

\section{BIBLIOGRAFÍA}

Amigo Roberto, Battistozzi Ana María \& FragAsso Lucas (2011), Escenas de los 80. Los primeros años, Buenos Aires: Librería Proa.

ANDRADE Javier (1987), "La organización negra es el espejo que refleja la miseria del futuro", La Razón, Buenos Aires, 29 de julio de 1987.

BAK-GELER Tibor (2003), “Epistemología teatral”, Revista de la Asociación mexicana de investigación teatral, 4, 81-88.

BADIOU Alain (2012), El refugio de la cultura (programa de Canal 7 - Televisión pública argentina, Osvaldo Quiroga), 13/05/2012, <www.youtube.com/watch?v=9252mkVtdB4> (consultado el 18 de septiembre de 2013).

BARTHES Roland, La muerte del autor (C. Fernández Medrano, trad.), Teoría Literaria, <http:// teorialiteraria2009.files.wordpress.com/2009/06/barthes-la-muerte-del-autor.pdf> (consultado 
el 20 de octubre de 2012). (Obra original publicada en 1968 bajo el título La Mort de l'auteur, Marseille: Manteia.).

Deleuze Gilles (1987), “¿Qué es el acto de creación?” (B. Preciozo, trad.), Conferencia en la cátedra del martes de la Fondation FEMIS, 17/05/1987, Paris, <www.proyectotrama.org/00/trama/ SaladeLectura/BIBLIOTECA/elacto.htm> (consultado el 9 de octubre de 2012). (Conferencia original pronunciada bajo el título “Qu'est-ce que l'acte de création?”, 1987.)

Dopazo Fernando, Archivo personal inédito.

DuBATTI Jorge (2007), Filosofía del teatro I: convivio, experiencia, subjetividad, Buenos Aires: Atuel.

FEDIUK Elka (2011), “Herencias y exilios”, D. Adame (ed.), Jerzy Grotowski. Miradas desde Latinoamérica (pp. 21-48), Universidad Veracruzana, Xalapa: Antonio Prieto Stambaugh. FouCAUlT Michel (2008), Las palabras y las cosas. Una arqueología de las ciencias humanas (E. C. Frost, trad.), Buenos Aires: Siglo XXI. (Obra original publicada en 1966 bajo el título Les Mots et les choses, Paris: Gallimard.)

GonZÁLEZ María Laura (2010), Postal inédita de Buenos Aires, Primera Mención del II Concurso Nacional de Ensayo AINCRIT, Actas II Jornadas nacionales de investigación y crítica teatral, Buenos Aires: Asociación Argentina de Investigación y Crítica Teatral, <http://aincrit.org/postalinedita-de-buenos-aires.html>.

Ouellet Pierre (2000), Poétique du regard: littérature, perception, identité, Québec: Septentrion.

Pessolano Carla (2012), “Construcción de Subjetividad poética del actor”, La revista del CCC, 16, < www.centrocultural.coop/revista/articulo/358/> (citado el 20 de noviembre de 2013).

Pessolano Carla (2013), "Subjetividad poética y prácticas creadoras: el actor en su zona reflexiva", Actas del X Congreso Argentino de Historia del Teatro Universal, Buenos Aires (en prensa).

PISANI Gachi (1986), “La organización negra, teatro de la demolición”, Clarín, Buenos Aires, 31 de octubre de 1986.

Pressbook (original) "La organización negra" sobre "La tirolesa obelisco".

QUignaRd Pascal (2007), entrevista con Cristian Warnken, TVN (Televisión Nacional de Chile), Programa Una belleza nueva, <www.unabellezanueva.org/wp-content/uploads/documentos/ entrevista-pascal-quignard.pdf> (consultado el 14 de abril de 2013).

QuilLET Françoise (dir.) (2011), Arts du spectacle. Identités métisses, Paris: L'Harmattan.

SCARANO Laura (2007), Palabras en el cuerpo: literatura y experiencia, Buenos Aires: Biblos.

SCARANO Laura (2008), "Provocaciones teóricas para el siglo xxi: La experiencia del poema", I Congreso Internacional de Literatura y Cultura Españolas Contemporáneas, Universidad Nacional de La Plata, Facultad de Humanidades y Ciencias de la Educación, Centro de Estudios de Teoría y Crítica Literaria, La Plata, <http://sedici.unlp.edu.ar/bitstream/handle/10915/16237/ Documento_completo.pdf?sequence=1> (consultado el 15 de mayo de 2013).

SCHÉRER René (1998), Regards sur Deleuze, Paris: Kimé. 


\section{NOTAS}

1. Nos basamos en la noción de Poética de Dubatti (2007): "La Poética es el estudio del acontecimiento teatral a partir del examen de la complejidad ontológica de la poíesis teatral y de la zona de experiencia que ésta funda en su relación pragmática con el convivio y la expectación. La Poética se preocupa entonces por estudiar simultánea e integradamente en una unidad: el trabajo humano para la constitución de la poética, la estructura, la concepción de teatro."

2. Tenemos en Argentina el claro ejemplo de "La organización negra", grupo de postdictadura que no sólo hacía pruebas escénicas sino que además tenía una gran indagación acerca de su propia práctica, detallando todos sus procedimientos en glosarios y codificaciones de las mismas, ver Pessolano (2011), La organización negra: Escena de cuerpos presentes en la Postdictadura argentina (inédito).

3. Luego veremos porqué utilizamos este término para denominar a los intérpretes.

4. "El que venía desprevenido cruzando o los que estaban en los autos veían eso y se les paraba el mundo, eran segundos interminables" (Entrevista a Fernando Dopazo por Carla Pessolano el 15 de octubre de 2010).

5. Entrevista con Fernando Dopazo por Carla Pessolano el 15 de octubre de 2010.

6. Ibídem.

7. Otro elemento que utiliza el grupo para alejarse de lo que llamaban teatro "tradicional" es que se describían a sí mismos como Modelos Vivos y no como actores. En su glosario (que hace las veces de programa de mano del espectáculo UORC, 1986), detallan el término de la siguiente manera: "El modelo vivo es una estructura particular cuyo soporte fundamental es el cuerpo del actor y por ello mismo fuera de todo orden de complejidad. El modelo vivo es la confluencia en el cuerpo de un actor de una caracterización plástica y de determinada cualidad de movimiento."

8. Extractos del programa de difusión de la lista negra del centro de estudiantes de arte dramático de la ENAD, año 1984.

\section{RESÚMENES}

A partir de nuestra formación y práctica que incluye lo artístico en articulación con la investigación, nos proponemos plantear una sistematización de procesos actorales en función de la noción de subjetividad poética que venimos desarrollando desde hace algunos años. Tomamos como punto de partida para la misma la mirada que construye el artista acerca de su propia práctica para ver cuáles son las herramientas que utiliza éste para pensar y describir su praxis. Para la aplicación de la noción utilizaremos un grupo que es un referente muy singular de la época de Postdictadura inmediata en Argentina, La Organización Negra (1984), grupo caracterizado por sus intervenciones urbanas y sus espectáculos "de choque", y que se autodescribe a partir de un glosario detallado y profundamente reflexivo.

À partir de notre formation et de notre expérience qui articule les composantes artistique et scientifique, nous proposons une étude systématique de processus de jeu d'acteurs en fonction de la notion de subjectivité poétique, qui est notre objet d'étude depuis quelques années. Nous avons pris comme point de départ le regard élaboré par l'artiste sur ses propres pratiques afin de voir 
quels sont les outils qu'il utilise pour penser et décrire sa praxis. Pour l'application de cette notion, nous utilisons un groupe théâtral qui est un référent singulier de l'époque de l'immédiate post-dictature argentine, La Organización Negra (L'Organisation noire), troupe caractérisée par ses interventions urbaines et ses spectacles de choc, et qui s'auto-décrit à partir d'un glossaire détaillé et profondément réflexif.

From my academic training and my experience that combine the artistic and the scientific components, I propose a systematic study of the acting process according to the notion of poetical subjectivity, that has been the object of our investigations for a few years. We took as a starting point the artist's vision of his own practice in order to see what are the tools he uses to think and describe his praxis. For the application of this notion, I refer to a theatre group that serves as a singular reference of the immediate Argentina post-dictatorship era, La Organización Negra (The Black Organization), a troupe characterised by its urban interventions and its provocative plays, and that describes itself buy using a detailed and deeply reflective glossary.

\section{ÍNDICE}

Mots-clés: subjectivité poétique, pratique théâtrale, post-dictature argentine, Organización Negra

Palabras claves: subjetividad poética, práctica teatral, postdictadura argentina, Organización Negra

Keywords: poetical subjectivity, theatre practice, Argentina post-dictatorship, Organización Negra

\section{AUTOR}

\section{CARLA PESSOLANO}

Actriz, Centro Cultural de la Cooperación, Grupo de Estudios de Teatro Iberoamericano y Argentino, Universidad de Buenos Aires, Université Paris 1 Panthéon-Sorbonne 